at which $\mathrm{MZ}$ twins are initiated. Anencephaly is least common in dichorionic $\mathrm{MZ}$ pairs and most common in conjoined and other monoamniotic pairs. ${ }^{10}$ (It is assumed that the closer in time that an anomalous event occurs to a developmental process, the more likely that process is to be affected deleteriously.)

(3) The raised concordance rate for anencephaly in $\mathrm{MZ}$ twins but not $\mathrm{DZ}$ twins, bearing in mind the sib risk. ${ }^{11}$

(4) The low sex ratio of spina bifida cases that occur in twins. ${ }^{12}$

It has been suggested that the deleterious effect of anomalous $\mathrm{X}$ inactivation on neural tube development is mediated by environmental factors. ${ }^{2}$ This would explain the fact that when anencephaly rates vary with a factor (for example, social class, season, region, time, maternal age, parity, race) the sex ratio of cases varies too ${ }^{13}$ : when rates are high, sex ratios are low, suggesting that environmental cofactors (together with anomalous $\mathrm{X}$ inactivation) are responsible for varying proportions of female cases.

The closure of the neural tube is a directional process occurring in general a few days after $\mathrm{X}$ inactivation and $M Z$ twinning events. It was suggested above that the closer in time that an anomalous event occurs before a developmental process, the more likely that process is to be affected deleteriously. If this were so, then anencephaly (being initiated closer in time than spina bifida to $X$ inactivation) would be expected to be more frequently caused by anomalous $\mathrm{X}$ inactivation. This would explain (1) the generally lower sex ratio of anencephaly cases than spina bifida cases, ${ }^{12}{ }^{13}(2)$ the fact that anencephaly is more closely related to MZ twinning than is spina bifida, ${ }^{10}$ and (3) the rather general lack of association between the sex ratio of spina bifida cases (in contrast with anencephaly cases) and incidence rates. ${ }^{12}$

I am grateful to Dr Anne McLaren FRS for help.

William H JAMES

MRC Mammalian Development Unit, Wolfson House,

University College London, 4 Stephenson Way, London NWI $2 H E$.

\footnotetext{
References

${ }^{1}$ Burn J, Povey S, Boyd Y, et al. Duchenne muscular dystrophy in one of monozygotic twin girls. J Med Genet 1986;23:494-500.

2 Hall JG. Neural tube defects, sex ratios and $X$ inactivation. Lancet 1986;ii:1334-5.

3 James WH. Sex ratio in twin births. Ann Hum Biol 1975;2:36578.
}

4 James WH. Sex ratio and placentation in twins. Ann Hum Biol 1980;7:273-6.

${ }^{5}$ Boklage CE. On the timing of monozygotic twinning events. Prog Clin Biol Res 1981;69A:155-65.

6 James WH. Hormonal control of sex ratio. J Theor Biol 1986;118:427-41.

${ }^{7}$ Monk M. A stem-line model for cellular and chromosomal differentiation in early mouse development. Differentiation 1981;19:71-6.

${ }^{8}$ McLaren A. The embryo. In: Austin CR, Short RV, eds. Reproduction in mammals. Book 2. Embryonic and fetal development. Cambridge: Cambridge University Press, 1972: $1-42$.

9 James WH. Twinning and anencephaly. Ann Hum Biol 1976;3: 401-9.

10 James WH. Differences between the events preceding spina bifida and anencephaly. $J$ Med Genet 1981;18:17-21.

11 James WH. Concordance rates in twins for anencephaly. J Med Genet 1980;17:93-4.

12 James WH. The sex ratio in spina bifida. J Med Genet 1979;16:384-8

13 James WH. The sex ratio in anencephaly. J Med Genet 1979;16:129-33.

\section{Duchenne muscular dystrophy in one of monozygotic twin girls}

SIR,

Burn et al $^{1}$ refer to two cases of pseudohypertrophic muscular dystrophy cases and another of Christmas disease in one of monozygotic (MZ) 46, XX twin girls and add a further MZ 46, XX twin pair discordant for Duchenne muscular dystrophy. In this case they showed by somatic cell hybridisation that in one twin girl only the maternal $X$ chromosome was active, whereas in the other only the paternal one was active. Other MZ twins, discordant for colour blindness ${ }^{2}$ or G6PD deficiency, ${ }^{4}$ also support their contention that such discordance does not arise by chance after random $\mathrm{X}$ inactivation but as a result of an unusual pattern of unequal $\mathrm{X}$ chromosome inactivation: one female in whom (nearly?) all cells express the $\mathrm{X}$ chromosome with the related gene, and the other in whom this gene is inactivated. Extending the hypothesis of 'unequal lyonisation', they state that the abnormal segregation of cells might actually have caused $\mathrm{MZ}$ twinning. This extension, however, does not explain the not infrequent observation of $\mathrm{MZ}$ twins discordant for chromosome abnormalities, that is, heterokaryotypic twinning and, as they agree, the predicted preponderance of female MZ twins is not substantiated in $M Z$ twin samples.

The general phenomenon of structural aberrations of the $\mathrm{X}$ chromosome being associated with late replication and inactivation in Turner patients, currently explained by 'preferential' inactivation, led me to wonder if this unusual phenomenon might 
not be the result of a more fundamental process in the egg or blastocyst. ${ }^{5}$ This unusual non-random inactivation and the $\mathrm{MZ}$ twinning process do not need to have a cause and effect relationship, but both can be consequences of a factor in the ovum itself. The same applies for the fortuitous association with gonadal dysgenesis. In animal experiments on ageing of the egg before ovulation or fertilisation indeed, an increase of abnormal cleavage divisions leading to one egg twins and chromosomal nondisjunctions, as well as of gonadal dysgenesis, has been observed at the preimplantation stages and in mid-gestation, respectively. ${ }^{6-8}$

Backed by these animal experiments and by the phenomenon of MZ 46,XX twins discordant for colour vision defect ${ }^{2}$ (and particularly the pair associated with primary amenorrhoea ${ }^{3}$ ), I have postulated that ovopathy can lead to $M Z$ twinning associated or not with "a pathological course of the inactivation of a gonosome, causing its structural deficiency and eventually its loss". 3 This concept also explains the frequent association of $\mathrm{MZ}$ twinning with defects, 'syndromes of obscure aetiology', and discordant karyotypes. ${ }^{9}$

\section{P H JONGBLOET \\ Maria Roepaan, Centre for the Mentally Handicapped, Ottersum, and Institute of Human Genetics,} Free University, Amsterdam, The Netherlands.

\footnotetext{
References

' Burn J, Povey S, Boyd Y, et al. Duchenne muscular dystrophy in one of monozygotic twin girls. J Med Genet 1986;23:494-500.

2 Koulischer L, Zanen J, Meunier A. La théorie de Lyon peutelle expliquer la disparité exceptionellement observée de la perception colorée chez des jumelles univitellines? $C R$ ler Congres Int Neuro-Génétique et Neuro-Opht. Basel, New York: Karger, 1968:242-54.

${ }^{3}$ Philip J, Vogelius Andersen CH, Dreyer V, et al. Colour vision deficiency in one of two presumably monozygotic twins with secondary amenorrhoea. Ann Hum Genet 1969;33:185.

4 Phelan MC. Morton CC, Swenson PM, et al. Evidence for lyonization of G-6-PD in a monozygotic twin pair. Am J Hum Genet 1980;32:123A.

5 Jongbloet PH. Status Bonnevie-Ullrich and Turner's syndrome. Overripeness ovopathy as a unifying concept. Part 1. In: Mental and physical handicaps in connection with overripeness ovopathy. Chap 5. Leiden: H E Stenfert Kroese, 1971:80-94.

6 Witschi E. Overripeness of the egg as a cause of twinning and teratogenesis. Cancer Res 1952;12:763-8.

7 Mikamo K. Intrafollicular overripeness and teratologic development. Cytogenetics 1968;7:212-33.

${ }^{\star}$ Butcher RL. Experimentally induced gametopathies. In: Iffy L, Kaminetzky HA, eds. Principles and practice of obstetrics and perinatology, New York: John Wiley, 1981:339-49.

9 Jongbloet PH. Monozygotic twinning, structural defects, and syndromes 'of obscure etiology'. J Pediatr 1980;97:868-9.
}

These letters were shown to Dr Burn who replies as follows.

SIR,

I read with interest the two preceding letters. In our original paper the temptation to expand the hypothesis into the biology of twinning in general was resisted in view of the limited experimental data. Nevertheless, the widespread use of MZ twins as an experimental tool in genetics justifies rigorous examination of the underlying assumptions. James presents an elegant review of the excess of female pairs among MZ twins with the lowered sex ratio showing a progressive decline through the range of $\mathrm{MZ}$ twins from dichorionic to conjoined. The ability of the 'unequal $\mathrm{X}$ inactivation' theory to account for this female excess has prompted us to extend our experiments on $\mathrm{X}$ inactivation patterns into other $\mathrm{MZ}$ twins including a conjoined pair. The results of this study will not be available for some months. James notes that, while the precise timing of early $X$ inactivation is not known, equivalence to the mouse would put it at eight to 10 days. If this were the case, it would postdate dichorionic and most of monochorionic twinning, arguing against the clustering of $\mathrm{X}$ inactivated cells being a precipitant of developmental separation in the majority of $\mathrm{MZ}$ twins.

The letter from Jongbloet concentrates on the interesting phenomenon of ageing of the ovum. He presents evidence in favour of 'ovopathy' being a potential teratogenic influence, but regards the female excess in $\mathrm{MZ}$ twins as being more likely to be the consequence of preferential early loss of males. His letter does not offer a specific reason why there should be contrasting $X$ inactivation in the reported twin girls unless this clonal grouping caused the twinning.

A recent report of an excess of $M Z$ twins among the products of in vitro fertilisation, ${ }^{1}$ together with the demonstration that an experimentally induced delay in ovulation in the rabbit considerably increased the incidence of MZ twinning and chromosome defects, ${ }^{2}$ prompt me to wonder whether there may be an element of truth in all these arguments.

If delayed fertilisation has an adverse effect on development this may be because one part of the 'developmental clock' starts at ovum release rather than fertilisation. If the gap between these is greater than normal the cytoplasmic stimulus to differentiate might find the cell mass too small or 'immature' or both. In consequence the capacity to initiate more than one centre of development may be increased. If $X$ inactivation is influenced by the 'ovum clock', it too might occur at a relatively earlier stage of cell division when the smaller cell number might be expected to 'cluster' more readily. 